\title{
Personal radiation monitoring of occupationally exposed radiographers in the biggest tertiary referral hospital in Ghana
}

Benard Ohene Botwe ${ }^{1 *}$, William K. Antwi ${ }^{1}$, Kofi Kyei Adesi ${ }^{1}$, Samuel Anim-Sampong ${ }^{1}$, Alberta M. E. Dennis ${ }^{1}$, Benjamin Dabo Sarkodie ${ }^{2}$ and Samuel Yaw Opoku ${ }^{1}$

\begin{abstract}
Background: The use of radiation in the health sector is of tremendous diagnostic and therapeutic benefit to patients. However, scatter radiation associated with its use poses detrimental risks to occupational staff and other health personnel whose activities are associated with the use of radiation. Therefore, there is a need to ensure effective monitoring of occupational exposed health personnel. Presently, the effectiveness of this programme at the biggest tertiary hospital in Ghana is however unclear.

Aim: The aim of this study was to investigate if occupationally exposed radiographers in the biggest tertiary referral hospital in Ghana were monitored in compliance with international regulations.

Methods: A quantitative descriptive survey design was used to obtain data on radiation monitoring in the biggest tertiary referral hospital in Ghana from February 2014 to April 2014. Two different tools, observation and questionnaire, were employed for data collection from 50 radiographers purposively sampled in the study. The data was analysed with Microsoft Excel 2010.

Results: A $100 \%$ response rate was obtained. All respondents were monitored by means of a TLD badge except $4(8 \%)$ who did not have any personal radiation monitoring device. Although $86 \%$ of respondents confirmed that their personnel dosimeters were collected for reading after 3 months of use, all the respondents however, did not receive TLD readings feedback until after 3 or more months. In particular, $38 \%$ of diagnostic radiographers claimed they never received any feedback, while $66 \%$ respondents indicated radiation monitoring in their various departments were unsatisfactory. Delays from the service provider (regulatory body) were identified as the causes of irregularities in supply of dosimeters and monitoring feedback.
\end{abstract}

Conclusion: Radiation monitoring of occupational personnel at the biggest tertiary hospital was unsatisfactory and did not meet required standards. Hospital management and the regulatory body should ensure strict compliance with international regulations for purposes of achieving occupational radiation safety.

Keywords: Radiation safety, Monitoring, Dosimeters, Radiographers

\footnotetext{
* Correspondence: bebotwe@ug.edu.gh

${ }^{1}$ Department of Radiography, School of Biomedical \& Allied Health Sciences, University of Ghana, P.O Box KB 143, Accra, Ghana

Full list of author information is available at the end of the article
} 


\section{Background}

The diagnostic role of $\mathrm{x}$-rays in contemporary medicine is well established although $\mathrm{x}$-rays are a known and proven human carcinogen [1]. Worldwide, the annual per capital effective dose has doubled over the past decade due to the daily increase in diagnostic procedures [2]. This implies that more people are exposed to ionizing radiation for either diagnostic or therapeutic purposes. Ghana is not exempted from this increasing diagnostic use of $\mathrm{x}$-rays with examinations ranging from six to eleven per thousand population recorded from 1990 to 1996 [3].

Due to the detrimental effects of $\mathrm{x}$-rays, it is necessary to keep all radiation exposures and hence radiation doses to occupational (staff), medical (patients) and public (general public) as low as reasonably achievable (ALARA) or practicable (ALARP) [4]. This can only be achieved if there is strict adherence to all regulations pertaining to the administration of $\mathrm{x}$-rays for the safety of users and recipients. In Ghana, radiation safety at workplaces can be accomplished if there is optimization of occupational exposures and the establishment of radiation protection programmes [5]. Monitoring of external radiation is therefore essential in assessing occupational exposure in therapeutic and diagnostic radiology [6]. Technological advancements in the use of radiation in medicine pose new challenges for radiation protection to both patients and workers [7]. Occupational exposure has been described as the worker exposure received during a period of work [8, 9]. Medical radiation workers, the earliest occupational group exposed to ionizing radiation, comprise the highest number of radiation workers in Ghana and about 2.3 million worldwide $[5,10,11]$.

Persons potentially exposed to radiation as a result of work to more than three tenths of the occupational dose limit are occupationally exposed workers (OEWs) or radiation workers [12]. Occupational exposure to radiation can occur as a result of various human activities in a range of industries, medical institutions, educational and research establishments [9]. According to the World Health organization [13], OEWs often become vulnerable to detrimental work-related conditions in an attempt to attain personal career goals and organizational success. A study revealed that radiation exposure may have been a contributory factor to the onset of posterior sub capsular cataracts among radiologic technologists [14]. In Ireland, the majority of annual doses greater than $1 \mathrm{mSv}$ were received by workers in diagnostic radiology [15], while studies have revealed that radiology technologists had significant increase in female breast cancer [16-18] in the United States of America. It is therefore imperative that OEWs are effectively monitored and provided with suitable and adequate personal protective equipment which meets relevant regulations and international standards [19]. This position is emphasised by Goldstone [12], who indicated that OEWs are categorized as Category A or classified workers and must be subjected to comprehensive personnel radiation monitoring by approved dosimetry service providers. This is to determine the effective dose levels and provide information on the health risks of radiation workers and to ensure good practice.

Individuals normally exposed to medical radiation in controlled areas are medical physicists, radiographers, radiologists, radiation protection officers and radiology/ radiation nurses. Personnel monitoring is further recommended for frequent users of $\mathrm{x}$-ray systems and ancillary workers. As a result of potential stochastic or deterministic radiation effects which OEW are exposed to, principles of radiation protection and recommendations for personnel safety have been established by institutions such as the IAEA. This is enhanced by the monthly monitoring of individual effective dose [20].

In Ghana, ACT 588, The Atomic Energy Commission Act, 2000 was enacted by parliament to make proposals and advise the Government on legislation in the field of nuclear radiation and to supervise the carrying out of all requirements designed to secure the safety and health of radiation workers and the environment. The Radiation Protection Board (RPB) was therefore established by the amendment of the Ghana Atomic Energy Commission (GAEC) Act 588, 2000 and regulations LI_1559 of 1993, through the Provisional National Defence Council Law 308 and tasked to oversee all forms of ionizing radiation and safety issues of the country [21]. Additional functions include the initiation and drawing up of protection strategies on radiation, licensing users, supervising and monitoring the use of irradiating devices and radioactive materials. They are also into supplying and evaluation of dosimeters. To ensure its functionality, the RPB has issued safety guides to ensure the correct use of ionizing radiation. However, the question is: Are these safety guides on personnel monitoring working effectively or implemented?

Provision of regulations does not wholly deal with the problem of radiation protection and therefore management as well as personnel have their responsibilities regarding the enforcement of legislation [22, 23]. In Ghana, management of institutions where radiation is used have the role of developing policy to indicate commitment to optimization of protection within the organization by appropriate radiation programme [21]. This includes proving radiation protection measures and ensuring effective monitoring of radiation workers through provision of dosimeters while the personnel are to comply effectively with radiation protection standards [21].

An evaluation of personnel radiation monitoring in South-Eastern Nigeria revealed that personnel monitoring 
did not cover all employed personnel and the duration for supply of new dosimeters was three years [24]. Does this status of personnel monitoring reflect a comparable condition in Ghana?

In Ghana, the medical sector has the highest number of radiation workers. Studies on occupational dose accumulation revealed low dose accumulation during the process of practice [5]. Despite this evidence, there is little available data in Ghana on the regularity of use of personnel dosimeters by occupationally exposed health professionals and the status of monitoring as required by law. Could the lack of available literature confirm the discovery that regulations are known to have no strong influence in some countries? It is of necessity therefore to investigate if OEWs such as radiographers are effectively monitored for radiation safety.

\section{Methods}

This study was conducted in the radiotherapy (oncology) and the radiology departments of the biggest tertiary hospital in Ghana from February 2014 to April 2014. A quantitative descriptive survey design was used to obtain data. Two different tools; observation check list and questionnaire, tested for validity and reliability were employed for data collection. The observational tool in a form of checklist was used to retrieve data from dosimeter records on radiation monitoring from the departments. The check list assessed records on the following: the types of personal monitory devices used in the hospital, whether the personal monitory devices were collected for reading, how often they were sent for reading, whether feedback were brought to personnel and the level of frequency, were assessed. Items on the list also included whether there was national dose register at the facilities, whether the available readings were within normal range, whether radiation protection experts were available and whether sanctions were in place to deal with non-complying personnel with personal dose monitoring principles.

The 24-item, 4-sectioned questionnaire consisted of close and open ended questions that focused on capturing information on the state of personnel monitoring from the respondents. Section A sought demographic information such as gender, department of practice of respondents and years of clinical experience. Sections B and $\mathrm{C}$ sought information on provision of personnel dosimeters and regularity in the use of dosimeters, and the time elapsed before reading of personnel dosimeter, the provision of feedback to personnel and the availability of radiation experts respectively. Information regarding the awareness of personnel dosimetry regulations by respondents and whether personnel wear their badges during working hours all the time were assessed in section D. Also the level of satisfaction of radiation among respondents in their departments was addressed in section D.
All the radiographers in the hospital totalling fifty (from both diagnostic and therapy departments) were invited to participate. Purposively, all the radiographers were contacted in their working environments by the research team and issued with questionnaires, which were completed and returned to the research team by hand. For the observational study the research team approached the various departments within the hospital and evaluated practice and records with the check list items. The data collected was entered into Microsoft Excel spread sheet 2010, and descriptive analyses were generated.

\section{Ethics}

In accordance with ethical requirements and regulations, approval for the study was issued by the Ethics and Protocol Review Committee of the School of Biomedical \& Allied Health Sciences. Permission to carry out the study was also granted by the radiotherapy and the radiology departments of the teaching hospital. Participants were made to understand that their involvement in this study were voluntary and could however withdraw their participation at any time. In addition, they were assured anonymity and confidentiality of all their personal information. All the participants willingly consented to the study.

\section{Results}

All the radiographers (100\%) consisting of 27 females (54.0\%) and $23(46.0 \%)$ males participated in the study, and worked either as diagnostic radiographers $(n=38$, $76.0 \%)$ or therapeutic (oncology) radiographers $(n=12$, $24.0 \%$ ). The demographics (Table 1) showed that the majority $21(42 \%)$ had worked for 11 to 20 years, while 6 (12\%) had worked for 31 to 40 years and $2(4 \%)$ had worked for over 40 years.

All respondents were monitored by means of a TLD badge except $4(8 \%)$ who did not have any badge/device. Thirty two (64\%) of the respondents who worked in other hospitals were monitored at their previous employments. However, their current employers did not demand for previous dosimeter records. Twenty eight (56\%) of respondents were aware of regulations on monitoring of OEWs while the rest were not. However, $22(79 \%)$ of those who claimed awareness of the monitoring regulations did not know of any sanctions regarding personnel monitoring. 43 personnel representing $86 \%$ of the respondents admitted that they do not wear their TLD Badges at all times during work. The rest said otherwise. Contrary to IAEA and WHO recommendations that personal monitoring badges should be worn when in radiation environments [7], those who failed to wear TLD badges always during working hours indicated that they kept their TLD badges in the bags when not wearing them during work. Respondents' comments on 
Table 1 Demographics of respondents

\begin{tabular}{lllc}
\hline Demographic variable & & Number & Percent, $\%$ \\
\hline Gender & Male & 23 & 46.0 \\
& Female & 27 & 54.0 \\
& Total & 50 & 100.0 \\
Specialty of radiographers & Diagnostic & 38 & 76.0 \\
& Therapy & 12 & 24.0 \\
& (oncology) & & \\
& Total & 50 & 100.0 \\
Number of years of practice (years) & $11-20$ & 21 & 42.0 \\
& $21-30$ & 8 & 16.0 \\
& $31-40$ & 6 & 12.0 \\
& $\geq 40$ & 2 & 4.0 \\
& Total & 50 & 100.0 \\
\hline
\end{tabular}

receipt of feedback and duration taken before collection and analyses of personnel dosimeters, availability of radiation protection officers, level of satisfaction of monitoring and reasons for their dissatisfaction are as shown in Tables 2 and 3, and Figs. 1 and 2.

Dissatisfaction with the personal monitoring system in their centres was cited by 43 (86\%) of the respondents as a reason for their infrequent use (wear) of their TLD badges at work. Reasons for their dissatisfaction are indicated in Fig. 2.

\section{Observational findings}

It was observed that personal radiation monitoring devices used mainly in the diagnostic and the therapeutic departments of the hospital were thermoluminescent dosimeter (TLD) badges. The period of TLD collection for reading exceeded 3 months. Feedbacks were also not given on time. Records at the diagnostic department showed that the last time radiation monitoring reports or feedback was sent to radiography personnel was over a year ago. In the

Table 2 Cross tabulation of receipt of feedback and time for collection and analyses of personnel dosimeters

\begin{tabular}{lclc}
\hline Regularity & $\begin{array}{l}\text { TLD collection } \\
\text { for reading } \\
\text { Frequency (\%) }\end{array}$ & Department & $\begin{array}{l}\text { Feedback of personnel } \\
\text { monitoring device } \\
\text { Frequency (\%) }\end{array}$ \\
\hline Every 3 months & $0(0.0 \%)$ & Diagnostic & $0(0.0 \%)$ \\
& $2(4.0 \%)$ & Oncology & $0(0.0 \%)$ \\
3-6 months & $8(16.0 \%)$ & Diagnostic & $0(0.0 \%)$ \\
& $9(18.0 \%)$ & Oncology & $12(24.0 \%)$ \\
$>6$ months & $30(60.0 \%)$ & Diagnostic & $19(38.0 \%)$ \\
Never & $1(2.0 \%)$ & Oncology & $00(0.0 \%)$ \\
& $0(0.0 \%)$ & Diagnostic & $19(38.0 \%)$ \\
Total & $0(0.0 \%)$ & Oncology & $0(0.0 \%)$ \\
\hline
\end{tabular}

Table 3 Respondent satisfaction on personnel radiation monitoring

\begin{tabular}{lllll}
\hline $\begin{array}{lllll}\text { Department of } \\
\text { respondents }\end{array}$ & \multicolumn{2}{l}{ Level of satisfaction } & Total \\
\cline { 2 - 4 } & Very satisfied & Satisfied & Not satisfied & \\
\hline Diagnostic & 0 & 4 & 34 & 38 \\
Oncology & 1 & 5 & 7 & 12 \\
Total & 1 & 9 & 43 & 50 \\
\hline
\end{tabular}

oncology department, records showed that TLD badges were changed and feedback sent to the department. The changing period at the oncology site ranged from 3 to 6 months. National dose register was also present at the hospital although records were not up to date. At the radiotherapy centre, readings up to five years were available. At the diagnostic unit, only one (1) year period readings were available. In both departments not all the personnel had their readings consistently available in the dose register. The available readings were however within normal range as suggested by International Atomic Energy Agency [9, 19]. For personnel whose available readings were for a period 3 months (quarterly effective dose), the minimum and the maximum readings were 0.14 and $0.5 \mathrm{mSv}$ respectively and a mean value of $0.48 \mathrm{mSv}$ with a standard deviation (SD) 0.14. For those whose available readings were for a period 6 months, the minimum and the maximum effective dose readings were 0.26 and $0.83 \mathrm{mSv}$ respectively with a mean value of $0.63 \mathrm{mSv} \mathrm{SD} 0.37$. Also, for those whose available readings were one year, the minimum and the maximum effective dose readings were 0.28 and $0.97 \mathrm{mSv}$ respectively with a mean of $0.71 \mathrm{SD} 0.12$. Moreover, for those whose available readings were for a period of five years, their effective dose ranged from 2.43 to $5.97 \mathrm{mSv}$ with an average of $4.52 \mathrm{mSv}$ SD 1.5.

Only one radiation safety officer was available in the diagnostic and radiotherapy departments and based in the latter. Also, proper standard operating procedures were not in place in the two departments. A fine of US $\$ 55$ dollars was imposed by the regulatory body which also doubled as the service provider for loss of a TLD badge; this was however not enforced. Interim queries and warning letters were issued to personnel who submitted their TLD badges late in the oncology department. It was also noted that there were plans of applying sanctions to defaulting personnel in the diagnostic department.

\section{Discussion}

\section{Demographics}

The observed gender variation in this study is consistent with the literature [25] which reports more females than males in radiography. The population of radiographers in diagnostic radiography practice was much larger than those in therapy radiography. The above 


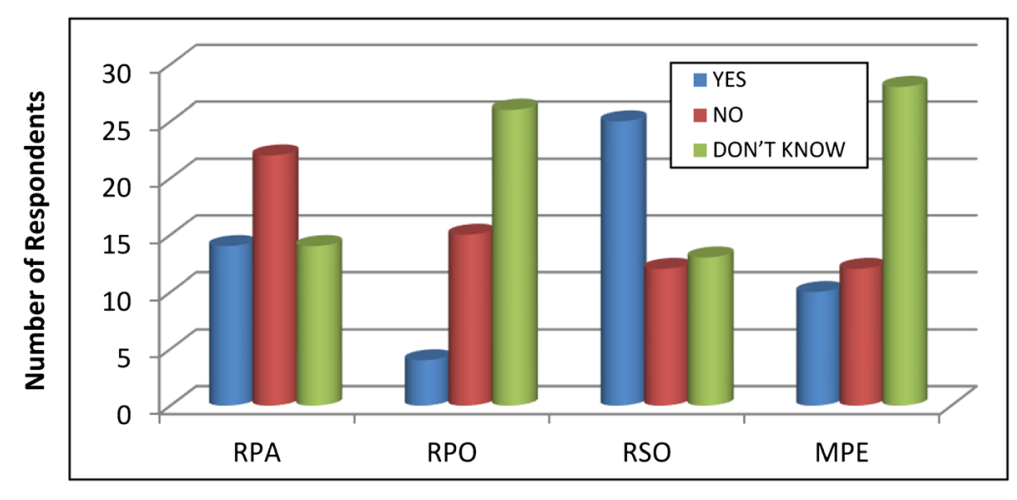

Type of Radiation Expert

Fig. 1 Availability of radiation protection officers. Key: RPA = Radiation Protection Advisor, RPO= Radiation Protection Officer, RSO = Radiation Safety Officer, MPE = Medical Physics Expert

finding is attributable to the fact that diagnostic radiography in Ghana is much older and hence has many radiographers trained and practising in this speciality. A probable reason for the small population of radiographers with over 40 years of working experience is that most of them had retired.

\section{Dosimeter use, time interval for dosimeter collection and receipt of feedback and record keeping}

The TLD badge with its property of cumulative dose recording was the common dosimeter used in the study site. It was observed that $8 \%$ did not have any personal monitoring device. This is similar to the report of Okaro and colleagues [24] that personnel monitoring did not cover all employed personnel in South-Eastern Nigeria. On the contrary, the IAEA $[9,19]$ safety guidelines require that every occupationally exposed worker must have a personal radiation monitoring device. It was noted that the period for collection of dosimeters exceeded 3 months for $80 \%$ of respondents (Table 2). This revealed a contradiction with local and international regulations which require that
TLD must be changed and submitted for reading every month or at most 3 months to prevent loss of stored information. Personnel cited inconsistencies in supply of dosimeters by the regulatory body as reason for the irregular periods of evaluation. It was also observed that the regulatory body's role as the sole provider of dosimetry services accounted for delays in supply and dosimeter readings. Although it was recognized that the service provider had made arrangements to ensure fast and convenient delivery of TLD badges it was noted that hospitals failed to return the same number of supplied dosimeters and thereby created artificial shortage.

The respondents (Table 2) indicated lack of prompt feedback until after 3 or more months post collection and analyses of personnel dosimeters. The situation was even worse at the diagnostic department where $38 \%$ of respondents claimed they have never received any feedback before. This is in contravention with local regulations which states that feedback must be sent promptly to all personnel and their respective departments after reading and analysis of badges. Investigations at the diagnostic

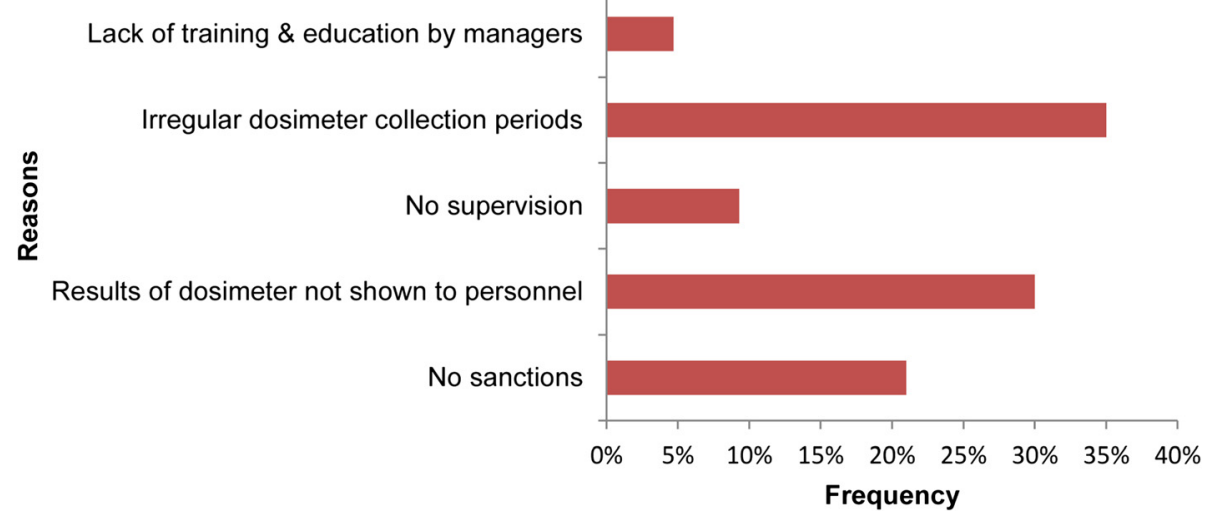

Fig. 2 Reasons for dissatisfaction amongst respondents 
department revealed that the latest time personnel received reports was over a year ago. Irregularities in the change of TLD badges were cited as the cause. In the oncology department, available records showed that TLD badges were frequently changed and feedback sent to the department with serial numbers and doses. The changing period at the oncology site ranged from 3 to 6 months. The delays and lack of feedback to personnel in the diagnostic department was attributed to poor supervision and a lack of knowledge of the appropriate authority to report radiation safety complaints. This further contravenes standards for keeping employer records as prescribed by the International Labour Organization [8]. Additionally, the national dose register was available at the departments, although the data in the diagnostic department was not up to date. However, the available data indicated that personnel effective doses were within the safety limits recommended by IAEA $[9,19]$. Meanwhile, the fact that about $86 \%$ of the personnel did not always wear their TLD badges during work hours but sometimes kept them in their bags could mean that personnel effective dose might be higher if they wore them.

\section{Monitoring of personnel with previous work experience}

Although personnel dosimeter records keeping is vital for dose assessment and corrective measures, it was observed the current employer did not demand dosimeter record histories of most previously monitored respondents at their previous work places. This suggests a lack of enforcement of standard regulations on employing radiation workers as required by the IAEA $[3,9]$.

\section{Availability of radiation experts}

Among the radiation experts, only the RSO was available in the study site. This finding agrees with a study in Southern Nigeria where radiation experts were available in only a few hospitals [24]. Some respondents however reported the presence of radiation experts such as RPO and MPE in the teaching hospital (Fig. 1). This was inaccurate though. It was noted that Ghana has RSOs and not RPOs as required by the IAEA. This was consistent with findings in local legislature and guidelines. It was further revealed that ideally, there should be 4 RSOs in the hospital (2 each in the diagnostic and oncology departments). However, only 1 RSO was available in the hospital. In large facilities such as the big teaching hospitals, the availability of radiation experts is vital to ensuring optimal radiation safety [26]. This includes ensuring that occupationally exposed radiographers always wore monitoring badges during working hours and personal radiation monitoring and radiation protection practices were effectively implemented. This scarcity of radiation experts is consistent with research findings in Southern Nigeria [24].

\section{Awareness of sanctions and regulations}

Sanctions or penalties must be in place to correct defaulting individuals. Most respondents were neither aware of regulations nor sanctions for OEWs. This could be due to the unavailability of standard operating procedures regarding personnel monitoring. It was noted that a fine of US $\$ 55$ was imposed for the loss of a TLD badge; however this rule was never enforced although queries and warning letters were issued to defaulting personnel for late submissions in the oncology department. Plans of applying sanctions to defaulting personnel in the diagnostic department were also noted.

\section{Satisfaction amongst respondents}

Respondents were generally dissatisfied with the level of personnel radiation monitoring at their departments as illustrated in Table 3. Most expressions of dissatisfaction were registered in the diagnostic department. Leading reasons for dissatisfaction were irregular dosimeter collection periods and the unavailability of feedback to personnel as revealed by the majority of the respondents (Fig. 2). Dissatisfaction of personnel could affect their work output and their eventual productivity which will affect the patient.

\section{Conclusion}

Radiation monitoring of OEWs at a tertiary hospital in Ghana did not meet international monitoring standards. It was observed that although almost all working personnel were supplied with personnel dosimeters, there were long periods of delay before dosimeters were collected for analysis. Additionally, feedbacks from the service provider were readily unavailable to personnel after TLD readings, and several of the radiographers were not well informed about regulations regarding personnel dosimeter usage. Many of them did not wear their TLD badges always during work and no sanctions were applied to defaulting personnel. There were also inadequate number of radiation experts at the hospital. These constitute contravention of local and international regulations regarding regularity in use of dosimeters and time period for collection of used dosimeters.

\section{Recommendations}

- The management of hospitals should employ the services of radiation experts to ensure that safety standards of operations are being carried out.

- There should be effective training and periodic retraining of personnel to enlighten them on personnel monitoring regulations and also ensure they are kept abreast with current trends and techniques. 
- Independent dosimeter service providers should be established to enable the regulatory body in function adequately.

- Concerned authorities such as the managers of health institutions, the radiation safety officers and the radiation protection Institute should ensure that radiographers as well as other occupationally exposed workers are always provided with and wear their personal monitoring devices.

\section{Competing interests}

The authors declared that they have no competing interests.

\section{Authors' contributions}

Author BOB and WKA designed the study, performed the statistical analysis, wrote the protocol and wrote the first draft of the manuscript. KAY, SAS, AMED and BDS helped to design the work, acquired and interpreted data, revised it for important intellectual content, and finally approved the version published. All authors read and approved the final manuscript.

\section{Acknowledgements}

The authorship of this article acknowledges with gratitude the support of the radiographers for agreeing to participate in the study.

\section{Author details}

'Department of Radiography, School of Biomedical \& Allied Health Sciences, University of Ghana, P.O Box KB 143, Accra, Ghana. ${ }^{2}$ University of Ghana School of Medicine and Dentistry, Accra, Ghana.

Received: 22 May 2015 Accepted: 17 August 2015

Published online: 21 October 2015

\section{References}

1. Hall EJ, Brenner DJ. Cancer Risks from Diagnostic Radiology. Br J Radiol. 2008:81(965):362-78.

2. Mettler FA, Bhargavan M, Faulkner K, Gilley DB, Gray JE, Ibbott GS, et al. Radiologic and nuclear medicine studies in the United States and worldwide: frequency, radiation dose, and comparison with other radiation sources_1950-2007. Radiology. 2009;253(2):520-31.

3. Schandorf C, Tetteh GK. Analysis of the status of $x$-ray diagnosis in Ghana. Br J Radiol. 1998;71:1040-8.

4. International Commission on Radiological Protection. 1990 Recommendations of the international commission on radiological protection, ICRP Publication 60. Oxford: Pergamon Press; 1991.

5. Gordon SW, Schandorf C, Yeboah J. Optimization of radiation protection for the control of occupational exposure in Ghana. Radiat Prot Dosimetry. 2010;16(12):1-8.

6. Sas-Bieniarz A, Obryk B, Pajor A, Kopeć R, Broda E, Budzanowski M. Finger doses in Poland in the view of the extremity ring dosimetry results of LADIS Dosimetric Service Krakow. 2010 [Online]Available at - http://www. irpa2010europe.com/proceedings/P08/P08-18.pdf. [Accessed on 30th January, 2014]

7. World Health Organization. Global initiative on radiation safety in healthcare settings. Technical meeting report 15th to 17th December. Geneva: WHO; 2008

8. International Labour Organization (ILO). Radiation protection of workers (Ionizing Radiation) - code of practice. Switzerland: ILO; 1987.

9. International Atomic Energy Agency. International basic safety standards for protection against ionizing radiation and for the safety of radiation sources, IAEA Safety Series No. 115. Vienna: IAEA; 1996.

10. Kumazawa S, Nelson DR, Richardson ACB. Occupational exposure to ionizing radiation in the United States: a comprehensive review for the years 1960-1985. In: United States Environmental Protection Agency, EPA52011-84-005. Washington DC: EPA; 1992. p. 100

11. International Commission on Radiological Protection. Avoidance of radiation injuries from medical interventional procedures. ICRP Publication 85. Ann ICRP. 2000;30(2):7-67.

12. Goldstone KE. Principles and control methods in practical radiation healthcare. New York: Oxford University Press; 1996. p. 79-80.
13. World Health Organization. Health and environment in sustainable development. Occupational Health at the Workplace. 1997. Available at: www.who.int/peh/occupationalhealth/occupationalhealth2htm. [Accessed 26th December, 2014].

14. Chodick G, Bekiroglu N, Hauptmann M, Alexander BH, Freedman DM, Doody MM, et al. Risk of cataract after exposure to low doses of ionizing radiation: A 20-year prospective cohort study among US radiologic technologists. Am J Epidemiol. 2008;168(6):620-31.

15. Colgan PA, Currivan L, Fenton D. An assessment of annual whole-body occupational radiation exposure in Ireland (1996-2005). Radiat Prot Dosimetry. 2008;128(1):12-20.

16. Mohan AK, Hauptmann M, Linet MS, Ron E, Lubin JH, Freedman DM, et al. Breast cancer mortality among female radiologic technologists in the United States. J Natl Cancer Inst. 2002;94(12):943-8.

17. Sigurdson AJ, Doody MM, Rao RS, Freedman DM, Alexander BH Hauptmann $\mathrm{M}$, et al. Cancer incidence in the U.S. radiologic technologists health study, 1983-1998. Cancer. 2003:97(12):3080-9.

18. Doody MM, Freedman DM, Alexander BH, Hauptmann M, Miller JS, Rao RS, et al. Breast cancer incidence in U.S. radiologic technologists. Cancer. 2006;106(12):2707-15.

19. International Atomic Energy Agency. Health effects and medical surveillance, Practical radiation technical manual. Austria: IAEA; 2004.

20. International Atomic Energy Agency. Optimization of radiation protection in the control of occupational exposure. Vienna: IAEA; 2002.

21. Ghana Radiation Protection and Safety Guide. Occupational radiation protection, Accra: Ghana Radiation protection board-G8. Accra: GAEC; 2000

22. Cunningham $\mathrm{R}$, llari $\mathrm{O}$, Ishiguro $\mathrm{H}$, Metivier $\mathrm{H}$, Paretzke $\mathrm{H}$, Pretre $\mathrm{S}$, et al. Radiation protection today and tomorrow: an assessment of the present status and future perspective of radiation protection. Organization for Economic Co-operation and Development (OECD). Paris: OECD Nuclear Energy Agency Publication; 2004.

23. Bury RF. The new ionizing radiation regulations - will they make a difference? Br J Radiol. 2000;12(4):255-61.

24. Okaro AO, Ohagwu CC, Njoku J. Evaluation of personnel radiation monitoring in South Eastern Nigeria. J Basic Appl Sci. 2009:2:49-53.

25. Schmidt LF. Gender roles, socialization, and hierarchy in an allied health profession: radiography students' constructs of self and the profession. Arizona: The University of Arizona; 2006.

26. Podgorsak EB. Radiation physics for medical physicists (Biological and Medical Physics Biomedical Engineering). New York, USA: Springer; 2010.

\section{Submit your next manuscript to BioMed Central and take full advantage of:}

- Convenient online submission

- Thorough peer review

- No space constraints or color figure charges

- Immediate publication on acceptance

- Inclusion in PubMed, CAS, Scopus and Google Scholar

- Research which is freely available for redistribution 